\title{
The investigation of medical and psychosocial problems of geriatric population in the urban area of Madhya Pradesh in India
}

\author{
Sanjay Kumar Gupta*, Atul Varshney, Sharad Chandra Tiwari, Mohan Shinde \\ Department of Community Medicine, Peoples College of Medical Sciences and Research Centre, Bhopal, India \\ Email: ${ }^{*}$ sanjaygupta2020@gmail.com
}

Received 12 January 2012; revised 9 March 2012; accepted 1 August 2012

\begin{abstract}
Globally, there are an estimated 605 million people aged 60 years and above. Improvements in health care facilities have brought longevity, which is considered to be one of the greatest achievements of the $20^{\text {th }}$ century. Objectives: To assess the morbidity pattern in geriatric people. Methodology: A community based cross sectional study. Results: Out of 208 aged 91 (43.7\%) were males, 117 (56.25\%) were females. Maximum number of males and females were from the age group 60 - 64 years. 117 (56.25\%) had chronic problems and $15(7.2 \%)$ acute. Musculo skeleton problem was the commonest $(63 \%)$ complaint both in males and females, followed by cardio vascular problem (44\%). Diabetes mellitus was more common in males than females and hypertension was more common in females than males. Chronic bronchitis was the commonest respiratory disorder in males (8.7\%). Total 20 (9.6\%) had psychological problems (depression), psychological problems more common in males $11(12 \%)$ than females 9 (7.7\%). Conclusion: The present study showed that chronic morbidity in elderly was significantly higher $(56.3 \%)$ than acute (7.2\%), most commonly affected system by chronic morbidity was musculo-skeletal followed by cardio vascular (CVS) and gastrointestinal (GIT). Psychological problems were more common in males $(12 \%)$ than in females $(7.7 \%)$. Psychological problems were more in lower socio-economic class-(V) than higher Class [1].
\end{abstract}

Keywords: Geriatric; Morbidity; Psychosocial; Urban

\section{INTRODUCTION}

Ageing is a natural, inevitable biological phenomenon. Community must learn to respect their grand elderly, understand them and treat them with honour, dignity and

\footnotetext{
"Corresponding author.
}

abundant love.

Globally, there are an estimated 605 million people aged 60 years and above. Improvements in health care facilities have brought longevity, which is considered to be one of the greatest achievements of the $20^{\text {th }}$ century. The ratio of older persons has changed dramatically from approximately one in fourteen in the fifties to about one in four at present. From 1990 to 2025, the elderly population in Asia will rise from 50 percent of world elderly to 58 percent, in Africa and Latin America from 5 - 7 percent, but in Europe the figure will drop from 19 to 12 percent of the world elderly [2-4]. The life span has increased in India from 32 years in 1947 to more than 62 years at present. From the morbidity point of view almost 50 percent of the Indian elderly have chronic diseases and 5\% suffer from immobility [5]. There are several vulnerable groups and a large disadvantaged group are elderly females, who are one of fastest growing segments and which will increase to become 4 times the current figure, by $2025[6,7]$. The challenge in the $21^{\text {st }}$ century is to delay the onset of disability and ensure optimal quality of life for older people.

A major component of the burden of illness for the elderly derives from prevalent chronic diseases. India in the epidemiological transition is facing a double burden of diseases both communicable and non communicable diseases where nutrition plays an important role. For the substantial impact on this burden, preventive health care strategies specific to the elderly need to be clearly formulated and tested. Current recommendations for periodic health examination and for preventive health care for the elderly include only minimal components for a geriatric preventive health care approach. Hence, this study was taken up with the objective of medical and psychosocial problems of geriatric among the urban area with a view to improve over health care services for them.

\section{OBJECTIVES}

1) To study the morbidity pattern among geriatrics; 
2) To assess various psychosocial factors in geriatric population;

3) To recommend measures to improve condition of geriatric population.

\section{MATERIAL AND METHOD}

It is a community based cross sectional study was carried out during the period of Oct. 2002 to Oct. 2003. This study was conducted in the urban health and family welfare centre (Lady Bhore centre) catchment area of Bhopal city. The cater area comprised of Fategarh, Saheed Nagar, Sazida Nagar, Idgah Hill, wards. In each area/ward 52 persons of geriatric age group were interviewed at home by using predesigned and pretested proforma. The reference population of universe for this study was geriatrics population of Catchment area of Lady Bhore centre, Bhopal. The urban family welfare centre covering the population of 65,978 with $5.09 \%$ (3358) of geriatric population (census 2001, [8,9]). $6 \%$ of geriatric population were taken as a sample size for the study 208 ( $>60$ years of age).

Eligibility criteria for selection of subject were those who had completed 60 years of age and above. Selection of the study subjects (208) were done by the systemic random sampling method by selecting every third house, first house was selected by random method (using currency note) in that way we were covered 5090 houses and got 208 geriatric people.

\section{DATA COLLECTION TOOL AND METHOD}

A study team comprised of post graduate student, interns, medical social worker, public health nurses, and attendants. Team was trained in the department of Commu- nity Medicine, Gandhi Medical College Bhopal, to collect uniform information regarding various parameters from the study subjects. The information was collected on a predesigned and pretested proforma though personal interview and general examination, data was collected by house to house visit. Each individual was told about the purpose of the study, and confidentiality of the information was assured. A detailed history was taken regarding present and past illness. The post graduate student and interns did a general physical examination. Body weight was measured in kilograms using a spring weighing machine to the nearest $0.5 \mathrm{~kg}$ with light cloths on. Blood pressure was measured twice using a mercury sphygmomanometer from the right arm with the elderly in the sitting position.

If high BP was detected, two more reading were taken on difference occasions to confirm hypertension. They were subsequently graded as normo-tensive. Systolic BP $<140$, diastolic $<90 \mathrm{~mm}$ of $\mathrm{Hg}$, Hypertensive systolic $\mathrm{BP}>140$ and diastolic $90 \mathrm{~mm}$ of $\mathrm{Hg}$ (WHO 1996) [9].

\section{DATA ANALYSIS}

The data was analyzed by computer using EPI-Info7 \& SPSS-9 software with the help of computer expert.

\section{OBSERVATIONS}

Two hundred and eight elderly people were studied from the study area. Out of 208 aged 91 (43.7\%) were males, 117 (56.25\%) were females. Maximum number of males and females were from the age group 60 - 64 years. In the age group of 80 years and above more number of males 9 (9.9\%) then females 8 (6.8\%). The mean age of the study group in male 68.8 years \& females was 67.4 years (Table 1).

Table 1. Distribution of respondents according to socio-demographic profile.

\begin{tabular}{|c|c|c|c|c|c|c|c|}
\hline \multirow{2}{*}{ Sl. No. } & \multirow{2}{*}{ Age } & \multicolumn{2}{|c|}{ Male } & \multicolumn{2}{|c|}{ Female } & \multicolumn{2}{|c|}{ Total } \\
\hline & & No. & $\%$ & No. & $\%$ & No. & $\%$ \\
\hline 1 & $60-64$ & 39 & 42.9 & 52 & 44.4 & 91 & 43.8 \\
\hline 2 & $65-69$ & 10 & 11 & 22 & 18.8 & 32 & 15.4 \\
\hline 3 & $70-74$ & 17 & 18.7 & 30 & 25.6 & 47 & 22.6 \\
\hline 4 & $75-79$ & 16 & 17.6 & 5 & 4.3 & 21 & 10.1 \\
\hline 5 & 80 and Above & 9 & 9.9 & 8 & 6.8 & 17 & 8.2 \\
\hline \multicolumn{8}{|c|}{ Educational Status } \\
\hline 1 & Illiterate & 38 & 41.8 & 82 & 70.1 & 120 & 57.7 \\
\hline 2 & Primary/Middle & 20 & 22 & 25 & 21.4 & 45 & 21.6 \\
\hline 3 & Metric & 14 & 15.4 & 6 & 5.1 & 20 & 9.6 \\
\hline 4 & Higher Secondary & 8 & 8.8 & 4 & 3.4 & 12 & 5.8 \\
\hline 5 & Graduate & 9 & 9.9 & 0 & 0 & 9 & 4.3 \\
\hline 6 & Professional & 2 & 2.2 & 0 & 0 & 2 & 0.96 \\
\hline
\end{tabular}


Table 2 shows that out of 208 aged in the study area, $40.7 \%$ males were care by their spouse during illness, while only $14.5 \%$ females were care by their spouses during illness.

$1.7 \%$ females stated that there was no one to look after them during illness.

Table 3 shows that out of 208 aged 117 (56.25\%) had chronic problems and 15 (7.2\%) acute, while rest of them was having no problem.

Table 4 shows that out of 208 aged more common problems of aged was musculo-skeleton 113 (62.9\%) followed by CVS 93 (44.7\%), GIT 91 (43.7\%), CNS 20 (9.6\%), respiratory system 19 (9.1\%), amongst the studied population.

Tables 5 shows that constipation was the most common complaint in all respondent and in both sexes amongst GIT disorders (12.2\%) male cases and 26.4\% female cases had a complained of constipation. Most common cardio vascular disorder in old age was hypertension (38.9\%), out of all CNS disorders cerebra vascular accident was more common in male cases (6.6\%) compared to female cases (2.6\%). Out of all locomotors disorders joint pain was the commonest complaint both in males and females. $54.7 \%$ of females complained of joint pain. Backache was more common in females (31.6\%) as compared to male (9.9\%).

Table 6 shows that 81 (89\%) males' cases and 81 (62.9\%) females cases had normal hearing. Impairment of hearing was found in 10 (11\%) males' cases and 31 (26.5\%) female cases. Deaf cases were $2.4 \%$ of total.

Out of 208 aged 20 (9.6\%) had psychological problems (depression). Psychological problems (Depression) more common in males $11(12 \%)$ than females $9(7.7 \%)$ (Table 7).

Table 2. Distribution of respondent according to care during illness.

\begin{tabular}{|c|c|c|c|c|c|c|c|}
\hline \multirow{2}{*}{ Sl. No. } & \multirow{2}{*}{ Care during Illness } & \multicolumn{2}{|c|}{ Male } & \multicolumn{2}{|c|}{ Female } & \multicolumn{2}{|c|}{ Total } \\
\hline & & No. & $\%$ & No. & $\%$ & No. & $\%$ \\
\hline 1 & Spouse & 37 & 40.7 & 17 & 14.5 & 54 & 26 \\
\hline 2 & Children & 39 & 42.9 & 77 & 65.8 & 116 & 55.8 \\
\hline 3 & Relative & 11 & 12.1 & 14 & 12 & 25 & 12 \\
\hline 4 & Friends \& Other & 4 & 4.4 & 7 & 5.98 & 11 & 5.2 \\
\hline 5 & None & 0 & 0.00 & 2 & 1.7 & 2 & 1.0 \\
\hline
\end{tabular}

Table 3. Distribution of aged according to morbidity.

\begin{tabular}{cccc}
\hline Sl. No. & Disease & No. & \% \\
\hline 1 & Acute & 15 & 7.2 \\
2 & Chronic & 117 & 56.3 \\
3 & Normal & 76 & 36.5 \\
& Total & 208 & 100 \\
\hline
\end{tabular}

Table 4. Distribution of respondent according to systemic disorder.

\begin{tabular}{clcc}
\hline Sl. No. & Systemic Disorders & No. & \% \\
\hline 1 & Gastrointestinal Tract & 91 & 43.7 \\
2 & Respiratory System & 19 & 9.1 \\
3 & Cardiovascular System & 93 & 44.7 \\
4 & Genito Uninary System & 11 & 5.2 \\
5 & Central Nerves System & 20 & 9.6 \\
6 & Musculo Skeleton & 131 & 62.9
\end{tabular}


Table 5. Distribution of respondent according to disorder (complain).

\begin{tabular}{|c|c|c|c|c|c|c|c|}
\hline \multirow{2}{*}{ Sl. No. } & \multirow{2}{*}{ Diseases } & \multicolumn{2}{|c|}{ Male $(\mathrm{n}=91)$} & \multicolumn{2}{|c|}{ Female $(n=117)$} & \multicolumn{2}{|c|}{ Total $(n=208)$} \\
\hline & & No. & $\%$ & No. & $\%$ & No. & $\%$ \\
\hline 1 & Diarrhoea & 3 & 3.2 & 12 & 10.2 & 15 & 7.2 \\
\hline 2 & Constipation & 11 & 12 & 31 & 26.4 & 42 & 20.1 \\
\hline 3 & Piles & 11 & 12 & 2 & 1.7 & 13 & 6.2 \\
\hline 4 & Lumps & 3 & 3.2 & 4 & 3.4 & 7 & 3.3 \\
\hline 5 & Chronic Bronchitis & 8 & 8.7 & 0 & 0.00 & 8 & 8 \\
\hline 6 & Bronchial Asthma & 6 & 6.6 & 5 & 4.3 & 11 & 5.3 \\
\hline 7 & Hypertension & 28 & 30.8 & 53 & 45.3 & 81 & 38.9 \\
\hline 8 & IHD & 9 & 9.9 & 0 & 0 & 9 & 4.3 \\
\hline 9 & CCF & 3 & 3.2 & 0 & 0 & 3 & 1.4 \\
\hline 10 & $\mathrm{BPH}$ & 4 & 4.4 & 0 & 0 & 4 & 1.9 \\
\hline 11 & Hernia & 2 & 2.2 & 5 & 4.3 & 7 & 3.4 \\
\hline 12 & $\begin{array}{l}\text { Cerebra Vascular } \\
\text { Accident }\end{array}$ & 6 & 6.6 & 3 & 2.6 & 9 & 4.3 \\
\hline 13 & Sciatica & 0 & 0 & 9 & 7.7 & 9 & 4.3 \\
\hline 14 & Arthritis & 21 & 23.1 & 64 & 54.7 & 85 & 40.9 \\
\hline 15 & Backache & 9 & 9.9 & 37 & 31.6 & 46 & 22.1 \\
\hline
\end{tabular}

Table 6. Distribution of aged according to their hearing status.

\begin{tabular}{|c|c|c|c|c|c|c|c|}
\hline \multirow{2}{*}{ Sl. No. } & \multirow{2}{*}{ Hearing Status } & \multicolumn{2}{|c|}{ Male } & \multicolumn{2}{|c|}{ Female } & \multicolumn{2}{|c|}{ Total } \\
\hline & & No. & $\%$ & No. & $\%$ & No. & $\%$ \\
\hline 1 & Normal & 81 & 89 & 81 & 69.2 & 162 & 77.9 \\
\hline 2 & Impaired & 10 & 11.0 & 31 & 26.5 & 41 & 19.7 \\
\hline \multirow[t]{2}{*}{3} & Deaf & 0 & 0.00 & 5 & 4.3 & 5 & 2.4 \\
\hline & Total & 91 & 100 & 117 & 100 & 208 & 100 \\
\hline
\end{tabular}

Table 7. Distribution of aged according to psychological condition (Geriatric depression scale).

\begin{tabular}{|c|c|c|c|c|c|c|c|}
\hline \multirow{2}{*}{ Sl. No. } & \multirow{2}{*}{ Psychological Condition } & \multicolumn{2}{|c|}{ Male } & \multicolumn{2}{|c|}{ Female } & \multicolumn{2}{|c|}{ Total } \\
\hline & & No. & $\%$ & No. & $\%$ & No. & $\%$ \\
\hline 1 & Present & 11 & 12 & 9 & 7.7 & 20 & 9.6 \\
\hline 2 & Absent & 80 & 88 & 108 & 92.3 & 188 & 90.4 \\
\hline
\end{tabular}




\section{DISCUSSION}

The well being of older persons has been mandated in article 41 [5] of the constitution of India, which directs that the state shall within the limits of its economic capacity and development; make effective provision for securing the right to public assistance in old age.

The study group comprised of males (43.8\%) and females (56.2\%). Vachharajani et al. (1978) at Bombay, Mehrotra et al. (1979) in Agra and Garg et al. (1981) in Merut have found $62.27 \%, 53.4 \%$ and $55.8 \%$ males respectively [10,11].

Mean age in the males was higher than female's 68.8 years, 67.4 years respectively. In the study of Garg et al. the mean age was 61.6 year for males and 62.6 years for females. The males was more literate $(58.2 \%)$ than females (29.9\%) in the present study $41.8 \%$ were males and $70.1 \%$ females were illiterate, Mitra et al. (1971) in Lucknow found $5.67 \%$ males \& $31.7 \%$ females. Ray (1975) found $13.6 \%$ males and $44.3 \%$ females, Mehrotra et al. (1979) reported $45.3 \%$ males and $79.1 \%$ females and Garg et al. (1981) found 5.4\% males and 59.2\% females were illiterate [12-15].

In the present study $58.3 \%$ males and $60.7 \%$ females aged were found addicted to one or more intoxicants. While the corresponding figure in urban study by Niyogi et al. (1971), Mitra et al. (1971), Ray (1975) and Garg (1981) were $52.87 \%, 29.3 \%, 44.8 \%$ and $44.2 \%$ respectively [12-15]. The commonest addiction in males was smoking $39.6 \%$ and females was tobacco chewing $46.2 \%$ in urban aged Ray (1975) and Vachharajani (1978) noted that it was being practice $21.81 \%$ and $20 \%$ respectively [14].

Zimbarg (1974) in a study in New York observed that there were $63 \%$ males and $35 \%$ females alcoholics in the age group 50 - 69 years and 50\% males and no females in the age group 70 years and above [16].

The commonest cause for limitation of mobility were diseases of bone and joint $20.7 \%$ followed by diseases cardio vascular system $2.4 \%$, diseases of CNS $1.4 \%$ and diseases of respiratory system (4.3\%) [17].

Garg et al. (1981) observed in a study in Meerut city that $33.9 \%$ aged were disabled at the time of survey $[7,10]$.

At the time of survey $3.2 \%$ males \& $10.2 \%$ females had complained of diarrhea. Which is similar to the finding of Mehrotara (1979) and Garg (1981) that constipation is a common complaint in the aged it was reported in $20.1 \%$ of cases and more common in females than males? Vachharajani et al. (1978) have reported obstinate constipation in $21.8 \%$ aged $[10,11]$.

Chronic bronchitis and bronchial asthma were found as commonest respiratory disease in old age. Prevalence of these diseases was found to be $8.7 \%$ and $6.6 \%$ respecttively.
Diseases of cardio vascular system is rising in the present study prevalence of hypertension were $30.8 \%$ in males and $45.3 \%$ in females.

Vachharajani (1978) and Garg (1981) have observed hypertension in $16.4 \%$ and $16.5 \%$ respectively in urban area [7].

In the present study $6.6 \%$ males and $2.6 \%$ females had problems of cerebro vascular accident. There were hemiplegia and paraplegia more common in males $6.6 \%$ than females $2.6 \%$. Diabetes was detected in $23 \%$ males and $11 \%$ female's elderly cases.

Vachharajani (1978) in a study of elderly in Bombay detected diabetes in $27.27 \%$ cases, while Garg was reported diabetes in $4.2 \%$ aged in a study of Meerut.

In the present study $12 \%$ males and $7.7 \%$ females had psychological problems. Psychological problems were more common in males than female aged.

\section{CONCLUSIONS}

The present study showed that chronic morbidity in elderly was significantly higher (56.3\%) than acute (7.2\%) most commonly affected system by chronic morbidity was musculo skeletal followed by cardio vascular (CVS) and gastrointestinal (GIT). Psychological problems were more common in males $(12 \%)$ than in females $(7.7 \%)$. Psychological problems were more in lower socio-economic class V (poorer) than in Class-I (Richer).

A significant higher number of aged was not having any social security. Knowledge about old age homes was poor in both males \& females and level of knowledge was found equal.

\section{REFERENCES}

[1] Chandra, S. (1974) A “demographic projection” at the seminar on "medical" (Profession and population problem at the AIIMS).

[2] Bose, A.B. and Saxena, P.C. (1946) Some characteristics of the aged population in the rural society. Journal of Family Welfare, 10, 33.

[3] Ferguson Anderson, W. (1971) Practical management of the Elderly. 2nd Edition, Blackwell Scientific Publication, Oxford.

[4] Berman, P.A. (1972) The aging gut. Geriatrics, 27, 86.

[5] Adding, B.N. (1982) Adding life to years. Journal of Indian Medical Association, 78, 120.

[6] Rao, N.S.N. (1978) Elements of health statistics.

[7] Grag, B.S., Gupta, S.C., Mishra, S.N. and Singh, R.B. (1982) A Geriatric study of and urban area I. Journal of Public Health, 19, 74-85.

[8] Alok, R. (2001) Madhya pradesh population, health and development atlas.

[9] Parks, J.E. (2001) Textbook of preventive and social 
medicine. 17th Edition, Bhanot Publisher, Jabalpur.

[10] Grag, B.S. and Gupta, S.C. (1982) Growing old gracefully. Swasth-Hind, 16, 57-58.

[11] Mehrotra, S.K., et al. (1979) Urabn aged population a social study. Indian Journal of Public Health, 23, 71-75.

[12] Mahler, H. (1982) Adding life to years. Swasth-Hind, 16, 68.

[13] Mc Muller, M.J. and Taylor, P.D. (1971) Need for a knowledge and use of community services of a sample of

\section{RECOMMENDATIONS}

1) Joint family system should be promoted in the community by the social workers, religious leaders, planners, educators, voluntary health agencies, and society and community itself; the above mentioned group must take the responsibility of promoting this system to ensure emotional security amongst geriatric population.

2) Many old people are capable of working after retirement if suitable employment is found for them. It may be useful to extend vocational guidance services to them.

3) Present old age pension scheme should be given due publicity and rules for eligibility should be libe- the elderly. Geriatric Digest, 8, 18.

[14] Narain, B. (1979) Problem of the aged pub: The skin institute \& pub. Service charitable Trust. N-Block Greater Kailash Is New Delhi.

[15] Ray, S.C. (1975) A medico-social study of aged persons.

[16] Zimberg, R. (1974) Study of psychopathy. Journal of Geriatric Psychiatry, 2, 236-242.

[17] Sheard, A.V. (1971) Survey of the elderly in Scunthrobe. Journal of Public Health, 85, 208-218.

ralized.

4) Care of the aged should be reduced to medical care alone. Health policy must be interwoven with social and economic policy to achieve effective care.

5) Due to increasing life expectancy, establishment of geriatric department in Medical Colleges should be encouraged.

6) For social security old age insurance scheme should be promoted by Government. Govt. should take initiative to start insurance scheme free of cost for poorer or should below poverty line people and provision of minimum premium for others. Govt. also promote old age insurance scheme for those in Govt. services, public sector or private sector. 